\title{
O “ESVERDEAMENTO” DA CONVENÇÃO EUROPEIA DE DIREITOS HUMANOS: VÍCIOS E VIRTUDES
}

\author{
José Adércio Leite Sampaio ${ }^{1}$
}

\section{Resumo}

Não há uma previsão expressa do direito ao meio ambiente equilibrado na Convenção Europeia de Direitos Humanos (CEDH). Sem embargo, há diversas normas e políticas destinadas a promover em toda Europa uma proteção ambiental. A Corte Europeia de Direitos Humanos, embora não o reconheça como um direito implícito na $\mathrm{CEDH}$, tem-se valido dos direitos expressamente nela previstos, sobretudo do direito ao respeito à vida privada e familiar, para afirmar-lhe, de modo reflexo, a proteção. É o que tem sido chamado de "ecologização" ou "esverdeamento" da Convenção Europeia. Embora esse entendimento apresente seus problemas, tem sido um instrumento que, progressivamente, amplia a proteção daquele direito, tanto em seu aspecto substantivo, quanto em sua dimensão processual.

Palavras-chave: Corte Europeia de Direitos Humanos. Direito ao meio ambiente equilibrado. Ecologização da Convenção Europeia de Direitos Humanos. Direitos Humanos. Meio Ambiente.

\section{CONSIDERAÇÕES INICIAIS}

Embora os argumentos teóricos e as razões morais sejam muito fortes a favor do reconhecimento de um direito humano ao meio ambiente equilibrado, ainda não se formou um consenso de que, em sede internacional ou regional, ele exista. Em 2007, em uma conferência ministerial dos países da Ásia e Pacífico sobre o ambiente, a conclusão foi contrária à existência. No sistema interamericano de direitos humanos, assim como sucede no africano, há a afirmação expressa do direito, todavia, sem a possibilidade de questionamento direto perante os órgãos de aplicação pelos que o tenham por violado (SHELTON, 2015). Na Europa, o Conselho da Comissão de Ministros rejeitou propostas do Parlamento para adicionar um protocolo à Convenção Europeia de Direitos Humanos (CEDH) que o positiva em 2004 e 2010 (EUROPA, 2010a).

A Corte Europeia de Direitos Humanos ( $\mathrm{CtEDH})$ tampouco reconhece a existência do direito no âmbito da Convenção. A proteção do ambiente, tanto no sistema europeu quanto no interamericano de direitos humanos se tem dado de modo reflexo e indireto, como decorrência da violação de um direito expresso nas respectivas Convenções. É o que se tem chamado de "ecologização" ou "esverdeamento" (greening) dos

\footnotetext{
${ }^{1}$ Doutor em Direito pela Universidade Federal de Minas Gerais. Professor da Pontifícia Universidade Católica de Minas Gerais e da Escola Superior Dom Helder Câmara. E-mail: joseadercio.contato@gmail.com
} 
mecanismos existentes para a proteção dos direitos civis, políticos e, por vezes, dos econômicos, sociais e culturais, por elas, declarados (BOYLE, 2007). Um jeito, como diz Gomes (2010, p. 163), de "escrever verde por linhas tortas".

No presente trabalho, examinar-se-á o fenômeno na Europa, a partir do estudo das principais normas que definem a União Europeia, bem como das decisões da CtEDH. Adota-se uma metodologia analítica e dedutiva, fortemente desenvolvida sobre a jurisprudência e bibliografia acerca do assunto.

\section{O DIREITO AO AMBIENTE EQUILIBRADO NOS TRATADOS EUROPEUS}

Na União Europeia, não há o reconhecimento expresso do direito ao meio ambiente equilibrado, mas é notável a preocupação com o tema ambiental, ainda que na forma de diretrizes políticas a serem adotadas pelos Estados-Membros com algum nível de discricionariedade. O Ato Único Europeu de 1987 dedicara um título ao "Ambiente" que já estabelecia as bases de uma política ambiental comum. As revisões que se seguiram ampliaram e aprofundaram essas bases. O Tratado de Maastricht (1993) incluiu o tema no âmbito de ação oficial da UE.

O Tratado de Amsterdã (1999), por sua vez, instituiu o dever de transversalidade da proteção do ambiente, exigindo que todas as políticas setoriais tivessem em conta a promoção do desenvolvimento sustentável. Já o Tratado de Lisboa (2009), que promoveu alterações no Tratado da União Europeia e no Tratado da Comunidade Europeia, renomeando esse último como Tratado de Funcionamento da União Europeia, tratou da matéria sob diversas perspectivas. Como objetivos específicos, estabeleceu, no âmbito do TUE (EUROPA, 2009a), o “empenho no desenvolvimento sustentável da Europa, assente (...) num elevado nível de proteção e de melhoramento da qualidade do ambiente" (art. $\left.3^{\circ}, 3\right)$; bem como, nas suas relações com o resto do mundo, a contribuição para preservar e melhorar a qualidade do ambiente e a gestão sustentável dos recursos naturais em escala mundial, a fim de assegurar o "desenvolvimento sustentável do planeta" (arts. $3^{\circ}$, 5; 21, 2, f).

No artigo 11 do TFUE (2009b), impôs-se o dever de a proteção do ambiente ser integrada com a definição e execução das políticas e ações da União, em especial com o objetivo de promover o desenvolvimento sustentável. No âmbito de repartição de competências, estabeleceu-se a partilha, entre a União e os EstadosMembros, do ambiente e da agricultura e pescas, com exceção da conservação dos recursos biológicos do mar, no tocante à política comum das pescas (art. $3^{\circ}, 1, \mathrm{~d}$ ) que é de atribuição exclusiva da União (arts. $3^{\circ}, 1, \mathrm{~d}$; e $4^{\circ}, 2$, d e e). Reconheceram-se, ainda, os princípios da precaução e da ação preventiva, da correção, prioritariamente na fonte, dos danos causados ao ambiente e do poluidor-pagador (art. 191.2). Coube também ao Tratado atribuir força jurídica vinculante à Carta de Direitos Fundamentais de 2000 (art. 6.1, TUE) e promover a adesão da União à Convenção Europeia de Direitos Humanos (art. 6.2, TUE).

A Carta estabelece uma linha propositiva de ação mais que uma enunciação normativa de conteúdo vol.10, nº. 02, Rio de Janeiro, 2017.pp. 779-800 
preciso e exigivel sobre o assunto. De acordo com o seu artigo 37, à semelhança do que dispõe o artigo $2^{\circ}$ do TUE, as políticas da União deverão integrar e garantir, "em conformidade com o princípio do desenvolvimento sustentável, um alto nível de proteção do meio ambiente e a melhoria de sua qualidade" (EUROPA, 2000). A Convenção Europeia de Direitos Humanos tampouco faz menção ao direito ao meio ambiente equilibrado, embora tenham sido vários os esforços para sua inclusão, inclusive recentemente (EUROPA, 2010; SHELTON, 2015, p. 18-19). Em resumo, não há uma fonte expressa de reconhecimento do direito ao meio ambiente equilibrado em seu sentido substantivo. É notável, por outro lado, que mais de duas centenas de instrumentos normativos, emitidos pelos órgãos europeus, tratem com ênfase da questão ambiental (DOMíNGUEZ, 2006, p. 703).

Uma das mais importantes, no entanto, não tem natureza vinculante. Trata-se da Recomendação 1614 (2003) da Assembleia Parlamentar do Conselho da Europa, que orienta os governos dos Estados-Membros a garantirem uma proteção adequada à vida, à saúde, à vida privada e familiar, à integridade física e à propriedade privada das pessoas, nos termos dos artigos 2, 3 e 8 da Convenção Europeia dos Direitos do Homem e no artigo $1^{\circ}$ do seu Protocolo n. 1 , tendo em especial consideração a necessidade de proteger o meio ambiente; bem como valer-se de uma forma própria ou viável para reconhecer o direito humano a um ambiente saudável e limpo, incluindo a obrigação objetivo dos Estados de protegê-lo nas leis nacionais, de preferência, em nível constitucional (seção 9, I e II) (EUROPA, 2003e).

$\mathrm{O}$ aspecto processual do direito ao meio ambiente equilibrado, de informação ambiental e participação popular e social nos processos deliberativos sobre intervenções no meio ambiente e de acesso à Justiça, tem sido interpretado a partir de dispositivos da própria Convenção que tratam da informação, participação e acesso à Justiça de um modo geral. A Convenção de Aarhus, ademais, foi incorporada ao direito da União Europeia por meio das Diretiva 2003/4/CE, de 28 de janeiro de 2003, sobre o acesso do público às informações sobre ambiente; e da Diretiva 2003/35/CE, de 26 de maio 2003, sobre a participação pública na elaboração de certos planos e programas relativos ao ambiente, e acesso à Justiça (EUROPA, 2003g). Se o Tribunal de Justiça Europeu tem um papel importante no âmbito da proteção ambiental, valendo-se desse repertório normativo todo (JACOBS, 2006), a CtEDH, que é objeto do presente estudo, tem de atuar com base no parâmetro que the é permitido, a Convenção, recorrendo àquelas disposições comunitárias apenas como elementos auxiliares de exegese. Quando muito. 


\section{O DIREITO AO AMBIENTE EQUILIBRADO NA JURISPRUDENCIA DA CORTE EUROPEIA DE DIREITOS HUMANOS}

A ausência de um reconhecimento expresso do direito ao meio ambiente equilibrado em sentido material tem levado a Corte Europeia de Direitos Humanos a negá-lo como direito explícito e autônomo, capaz de, per si, justificar uma demanda. Em Kyrtatos v Grécia (EUROPA, 2003a) e em Atanasovv Bulgária (EUROPA, 2011 b), por exemplo, disse que nenhum dos direitos da Convenção fora concebido especificamente para garantir uma proteção geral ao ambiente. $\mathrm{O}$ que não significaria falta de proteção, a se considerar o melhor tratamento se daria no âmbito dos Estados e mesmo a possibilidade de, reflexamente, ser garantida pela violação de outros direitos convencionais expressamente reconhecidos ou como um limite legítimo à atividade econômica e ao direito de propriedade. Por outro lado, a sua dimensão processual tem sido objeto de vários pronunciamentos da Corte, embora também entrelaçada com os mesmos direitos em que aparece envolvido o direito substantivo, além de fontes próprias dentro da Convenção.

\section{A proteção reflexa do direito ao meio ambiente equilibrado pela Corte de Estrasburgo}

Até final da década de setenta do século passado, tanto a Comissão quanto a Corte Europeia de Direitos Humanos recusavam a conhecer de demandas que veiculassem problemas ambientais, sob argumento de que a Convenção Europeia não tratava do tema (NOGUERA, 2012, p.152). Essa orientação se foi mudando ao longo da década seguinte, passando-se a reconhecer uma proteção reflexa tanto de um conteúdo substantivo do direito ao meio ambiente equilibrado, quanto de seus aspectos processuais.

\section{A proteção reflexa do direito substantivo ao meio ambiente equilibrado}

Embora não reconheça um direito ao meio ambiente equilibrado autônomo, a Corte de Estrasburgo passou-lhe a conferir relativo grau de proteção, por meio da garantia de outros direitos violados por ações ou omissões, patrocinadas ou toleradas pelos Estados. É verdade que, em princípio, apresentara resistência a fazê-lo mesmo desse modo indireto, conferindo grande margem de discricionariedade às autoridades locais em benefício da atividade econômica. O caso Powell e Rayner v. Reino Unido (EUROPA, 1990) é sintomático a esse respeito.

Naquela ocasião, discutia-se se as atividades de construção de um grande aeroporto (Heathrow) nas imediações de uma região populosa não violavam o meio ambiente e o direito à vida privada e familiar dos moradores da vizinhança. Embora a Corte tivesse reconhecido que o Estado britânico devesse adotar as medidas razoáveis e apropriadas de modo a garantir aos moradores o respeito a sua vida privada e familiar, assegurado pelo artigo 8.1 da Convenção Europeia, considerou um objetivo legítimo do Estado a construção do aeroporto, 
mesmo que causasse incômodos às vizinhanças e um "impacto negativo sobre o meio ambiente" (EUROPA, 1990, \$\$ 40-42). Esse entendimento de tolerabilidade do dano ou do risco de certas atividades era reforçado pela ausência de dados confiáveis ou que atribuíssem com relativo grau de certeza, pelo menos, a ponto de convencer os juízes, de que havia um nexo causal entre o alegado prejuízo ou dano e a atividade desenvolvida.

A antiga Comissão Europeia de Direitos Humanos, em diversas ocasiões, rejeitou pedidos que eram fundados no risco de exposição à radiação nuclear, por exemplo, pelos testes atômicos no atol de Mururoa na Polinésia Francesa (EUROPA, 1995), pela proximidade de uma estação de energia nuclear (EUROPA, 1997a) ou do transporte de resíduos nucleares (EUROPA, 1996a), afirmando que muitas atividades humanas produziriam riscos à saúde. Para que houvesse, todavia, consequências jurídicas, era necessária a demonstração de que tais atividades, de fato, houvessem causado um dano direto à saúde das pessoas ou, pelo menos, a possibilidade iminente de sua ocorrência. $\mathrm{O}$ argumento também fora usado pela Corte de Estrasburgo, para afastar a responsabilidade do Estado pela exposição à radiação durante um teste nuclear e o desenvolvimento de leucemia por um recorrente (EUROPA, 1998c).

Essas decisões foram tomadas já no curso dos anos 1990. Havia, no entanto, um precedente que, com o passar do tempo, serviria como marco do processo do que passou a se chamar de "ecologização", "ambientalização" ou "esverdeamento" dos direitos reconhecidos pela Convenção (BOYLE, 2007). Em 1994, a Corte reconheceu violação do artigo $8^{\circ}$ (direito à vida privada e familiar) da Convenção, pelos odores, ruídos e fumaças poluentes, causados por uma estação de tratamento de resíduos sólidos e líquidos, situada a poucos metros do domicílio da requerente.

Como sucedeu nesse caso, a proteção ao direito ao meio ambiente equilibrado se faz reflexamente ao resguardo do direito à vida privada e familiar, mas, em outros, o direito à vida pode estar em jogo. Há de se observar ainda um terceiro grupo de casos que identificam na proteção ambiental um interesse coletivo ou público legítimo a restringir outros direitos reconhecidos pela Convenção.

Direito à vida privada e familiar

Já se mencionou o caso López Ostra v. Espanha (EUROPA, 1994a), em que, pela primeira vez, a Corte entendeu que atividade poluente violava o direito à vida privada e familiar dos moradores a ela vizinhos. Em em julho de 1988, a prefeitura da cidade de Lorca havia construído uma estação de tratamento de resíduos líquidos e sólidos com vistas a resolver um problema ambiental sério, criado pela concentração de curtumes. Assim que começou a operar, a estação mostrou-se um remédio de muitos efeitos colaterais, pois logo apareceram outros problemas por ela causados. Os vizinhos alegavam incômodo com o barulho, o cheiro e a fumaça, bem como registros de problemas de saúde. Houve cessação parcial da atividade já em setembro daquele ano, mas não foi o 
suficiente para solucionar os transtornos. Processos administrativos e judiciais foram instaurados para que houvesse uma solução definitiva, mas sem êxito.

Entre fevereiro de 1992 e fevereiro de 1993, o município custeou a remoção e a moradia da família no centro da cidade. A Corte, no entanto, considerou que a família López Ostra se submetera a sérios inconvenientes causados pela estação durante três anos antes de receber a oferta municipal de mudança de residência. A atitude da municipalidade, atenuada pela remoção, ainda que tardia, da família, mas agravada pelo fato de ter impugnado os processos movidos para solução do problema, não conseguira alcançar um equilíbrio adequado entre o interesse do bem-estar econômico da cidade - o de ter uma estação de tratamento resíduos - e o pleno gozo da requerente do seu direito ao respeito da sua casa e a sua vida privada e familiar.

Mesmo que não houvesse atentado à saúde, afirmou a Corte, "a poluição ambiental grave pode afetar o bem-estar do indivíduo e impedi-lo de desfrutar de sua casa, de tal modo que fere a sua vida privada e familiar, sem, contudo, por em risco sua saúde" (EUROPA, 1994a, \51). ${ }^{2}$ Resolver um problema ambiental, criando outro não é a solução, portanto. É interessante notar que artigo convencional $8^{\circ}$ exige do Estado mais do que uma abstenção, de modo a não provocar um dano, mas também um dever de agir para que ele não ocorra. Esse duplo caráter da obrigação estatal não foi afirmado de modo expresso em López Ostra, mas, na linha de precedentes em relação a outros direitos, em Guerra v. Itália, julgado em 1998. O Estado não tomara providências para evitar a liberação de produtos químicos poluentes de uma fábrica nem informar a população a respeito dos riscos (EUROPA, 1998a).

Em 2001, no caso Hatton e outros v. Reino Unido, os problemas com o aeroporto de Heathrow, em Londres, vieram à discussão outra vez. A Terceira Seção da Corte concluiu que o Estado não conseguira obter um justo equilíbrio entre o bem-estar econômico do Reino Unido e o efetivo direito dos requerentes a gozarem de suas casas, de suas vidas privadas e familiares ${ }^{3}$. Essa decisão foi, contudo, revista pela composição plenária da Corte, após recurso do Reino Unido em 2003, e dela será tratada adiante (EUROPA, 2003d). Mas lançou mais um degrau no processo de afirmação da proteção reflexa do direito ao meio ambiente equilibrado.

Em 2002, em Öneryildiz v. Turquia (EUROPA, 2002), a orientação do primeiro julgado de Hatton foi aplicada, agora relacionada à explosão de gás metano no aterro sanitário de Umraniye em Istambul; assim também, no caso Moreno Gómez v. Espanha (EUROPA, 2004), em Mileva v. Bulgária, de 25/11/2010 (EUROPA, 2016, p. 16) e Bor v. Hungary, de 18/06/ 2013 (EUROPA, 2016, p. 18), relativamente à poluição sonora causada por um clube noturno, uma loja de computadores e trens, respectivamente; e, em 2009, no caso Tătar v. Romênia, sobre um desastre ecoló冈gico resultante das instalações de descarga de uma mina de ouro no

\footnotetext{
2 "[S] evere environmental pollution may affect individuals" well-being and prevent them from enjoying their homes in such a way as to affect their private and family life adversely, without, however, seriously endangering their health".

3 "The State failed to strike a fair balance between the United Kingdom's economic well-being and the applicants' effective enjoyment of their right to respect for their homes and their private and family lives" (EUROPA, 2001e, $\$ 107$ )
} 
Ri\} \bigotimes _ { o } \text { Sasar. Nesse caso, avançou-se a dizer que o Estado romeno não havia cumprido com o seu dever de prevenir } os riscos causados pela mina: "o princípio da precaução recomenda que os Estados não atrasem a adoção de medidas eficazes e proporcionais para evitar um risco de dano grave e irreversível ao meio ambiente mesmo na ausência de certeza científica ou técnica”. ${ }^{4}$ (EUROPA, 2009c, \$109).

É possível identificar na evolução da jurisprudência da Corte uma ampliação da proteção ambiental, descolando-a de reflexos à saúde, como já prenunciados em López Ostra, e, de certo modo, "abstrativando" (ou "objetivando") a aplicabilidade do artigo 8 o da Convenção, nomeadamente sobre o direito ao respeito pela vida privada e familiar. Em Taşkin v. Turquia (EUROPA, 2004a), afirmou-se que a inatividade do Estado para prevenir os riscos à saúde das pessoas e à integridade do ambiente de certas atividades perigosas, reconhecidos por um estudo de impacto ambiental, importava violação do direito à o respeito pela vida privada e familiar. Essa violação não ocorreria apenas com o dano ambiental consumado, mas também com a omissão em evitá-lo; tanto em face uma degradação grave da qualidade do ambiente, quanto diante dos efeitos nocivos de uma atividade perigosa, sobretudo quando forem mencionados num estudo de impacto ambiental. $\mathrm{O}$ artigo $8^{\circ}$ da Convenção conferiria uma proteção tanto ex post, quanto ex ante, diretamente à vida privada e familiar; e reflexamente, ao meio ambiente.

Noutro caso, envolvendo também a Turquia e julgado em 2006, Öçkan et al v. Turquia, a Corte decidiu que o Estado descumprira suas obrigações positivas de salvaguardar o direito ao respeito à vida privada e familiar, autorizando a atividade altamente poluente de uma aciaria, sem regular o exercício de tais atividades nem adotar medidas adequadas para proteger a saúde das pessoas. Chama atenção, no caso, o fato de que, embora, aparentemente, tenha seguido os limites de López Ostra, na verdade, não tratou da penetração das imissões nas casas, mas referiu-se à poluição do ar, cujos laudos apontavam relação com o aparecimento de certas doenças na região, prejudicando todos os habitantes, e, em consequência, reduzindo a qualidade de vida privada e familiar dos requerentes.

Em Di Sarno e Outros v. Italia (EUROPA, 2012), que tratou da "crise do lixo" na região da Campânia, Itália, reforçou-se o entendimento de que a poluição ou o dano ambiental, independentemente de causar mal à saúde, viola o direito ao respeito da vida privada e familiar. Entre 11 de fevereiro de 1994 a 31 de dezembro de 2009, o município de Somma Vesuviana viveu sob decreto de emergência, baixado em virtude das pilhas de lixo acumulado nas ruas. As providências de remoção e tratamento foram impugnadas pelo ministério público por fraudes, violação dos contratos, interrupção do serviço público e abuso de poder, dentre outros delitos. Após o esgotamento dos recursos internos, os requerentes levaram o assunto à Corte, alegando que o Estado não tomara

\footnotetext{
4 “[L]e principe de précaution recommande aux États de ne pas retarder l'adoption de mesures effectives et proportionnées visant à prévenir un risque de dommages graves et irréversibles à l'environnement en l'absence de certitude scientifique où technique”. Veja-se também Brincat and Others v. Malta: EUROPA, 2016, p. 9-10.
} 
as medidas necessárias para assegurar o bom funcionamento do serviço de coleta de lixo, causando sérios danos ao meio ambiente da região e riscos à vida e à saúde, bem como atentado à vida privada e familiar. A Corte, refutando o argumento governamental de que a crise se devera a motivo de força maior, afirmou que a incapacidade do Estado em garantir o funcionamento normal da coleta, processamento e depósito do lixo afetaram bem-estar dos demandantes. Em Brânduse v. Roménia, já se havia dito que odores desagradáveis produzidos por "lixões" violam o direito ao respeito à vida privada e familiar. O caso merece uma especial menção pelo fato de ser um pleito formulado por um prisioneiro e a casa ser a sua cela, o que não desmerece a proteção de sua qualidade de vida e bem-estar (EUROPA, 2009e) $)^{5}$.

Em Fadeyeva v. Rússia (EUROPA, 2005), embora fosse considerada a plausibilidade de que a saúde da requerente tivesse sido comprometida pela poluição produzida por uma fábrica de aço, a Corte afirmou não haver dúvidas de que os altos índices de poluentes produzidos haviam afetado adversamente a qualidade de vida dos moradores de uma casa nas vizinhanças da indústria, atentando contra o direito ao respeito da vida privada e familiar (\$ 88). E o Estado falhara em seu dever de agir para que a fábrica de aço não tivesse produzido tamanho dano ao ambiente: "A (...) responsabilidade do Estado em casos ambientais pode surgir a partir de uma falha de regulação da indústria privada"; e do seu dever de "tomar medidas razoáveis e apropriadas para proteger os direitos da recorrente nos termos do artigo 8, \$1 da Convenção" ${ }^{6}(\$ 89)$.

Ainda se deve mencionar Dzemyuk v. Ucrânia, em que se reconheceu violação ao direito ao respeito à vida privada, pela contaminação da água do subsolo, comprometendo o abastecimento domiciliar. A construção de um cemitério, sem as cautelas ambientais necessárias, havia sido a causa do problema, descumprindo o Estado o seu dever de adotar as ações necessárias para evitar que o fato ocorresse. "A poluição ambiental”, reiteraram os juízes, "pode afetar o bem-estar dos indivíduos e impedi-los de desfrutar de suas casas, afetando negativamente a sua vida privada e familiar, mesmo sem por seriamente em perigo a sua saúde” (EUROPA, 2014, \$ 88)7.

O direito ao respeito à vida privada e familiar é garantia e não limite à proteção ambiental. Pelo menos é o que se infere de uma série de casos, em que a Corte não viu problema na retirada forçada de ciganos que se instalaram, sem a necessária licença, em área previamente destinada pelo governo à implementação da política de cinturões verdes e à preservação da paisagem (EUROPA, 1996b; 2001a, b, c, d; 2003c). Embora reconhecesse

${ }^{5}$ O que foi reiterado em Florea v. Romania, de 14/09/2010; e Elefteriadis v. Romania, de 25/01/2011 (EUROPA, 2016, p. 4)

6" [T] he State's responsibility in environmental cases may arise from a failure to regulate private industry (...) [and] to take reasonable and appropriate measures to secure the applicant's rights under Article $8 \$ 1$ of the Convention." Ver no mesmo sentido Dubetska and Others v. Ukraine (EUROPA, 2011). Veja-se também Deeญs v. Hungary, de 09/11/2010: embora a vibração e o ruído causados pelo tráfego pesado na rua do reclamante não tivessem provocado danos à casa ou à saúde dos moradores, tinham, juntamente com a poluição e o cheiro, tornado a casa praticamente inabitável (EUROPA, 2016, p. 16).

7 "Environmental pollution may affect individuals' well-being and prevent them from enjoying their homes in such a way as to affect their private and family life adversely, without, however, seriously endangering their health". O abastecimento de água sem cuidados 
que se estava desenvolvendo um consenso na Europa e fora dela para proteger os direitos das minorias e a diversidade cultural, ele ainda não era bastante forte para superar a margem de apreciação que os Estados tinham para avaliar as circunstâncias dos casos concretos que envolvessem um interesse geral, como a proteção do meio ambiente, e os direitos de indivíduos e grupos. Em situações assim, a Corte não poderia interferir.

\section{Direito à vida}

O direito à vida pode ser ameaçado ou violado quando há um sério risco à qualidade ambiental ou um dano já ocorrido. No caso Öneryildiz v Turquia (EUROPA, 2002), há pouco mencionado, a Corte se baseou também na violação do direito à vida para responsabilizar o Estado turco das mortes causadas pela explosão de gás metano no aterro sanitário de Umraniye. As autoridades tinham conhecimento dos riscos que o depósito de lixo produzia ao meio ambiente e à "saúde dos seres humanos e animais" e nada fizeram para evitar o perigo real e imediato (\$\$ 56, 100-101).

A saúde é um direito próprio, todavia, pode ser visto também como uma decorrência do direito à vida. E a violação de um importar violação de outro. Se o comprometimento da saúde não levar à morte, pode, pelo menos, afetar a qualidade de vida. Diversos estudos revelam a incidência de doenças relacionada a poluentes, mas nem sempre é fácil provar o nexo causal em casos concretos. Em Fadeyeva v. Rússia (EUROPA, 2005), acontecera algo assim. A requerente não tinha prova de que a poluição produzida por uma fábrica de aço próxima à sua casa lhe causara os problemas de saúde. A Corte, porém, baseou-se em laudos que revelavam níveis de elementos tóxicos na região em que a requerente morava, bem como a sua correlação com o alto número casos de câncer dos moradores da área. Embora entendesse que a requerente não sofrera um dano especial e extraordinário, a combinação de evidências indiretas e presunções permitia concluir que "a saúde da requerente se deteriorara como resultado de sua exposição prolongada às emissões industriais..." ( $(88)^{8}$. No mínimo, poder-seia dizer que a poluição havia "afetado adversamente a sua qualidade de vida" ( $\$ 88)$. É certo que nesse como em outros casos, os juízes acabaram por identificar atentado ao artigo 8 e não a violação do artigo $2^{\circ}$, mas os argumentos utilizados remetem ao agravo do direito à vida, como, aliás, expressamente reconheceram os tribunais russos. A própria Corte costuma expressamente deixar de analisar essa violação, considerando o provimento com base no direito ao respeito à vida privada e familiar. Em Guerra v. Itália, por exemplo, ela chegou a discutir a violação do artigo $2^{\circ}$ da Convenção, mas preferiu dar razão aos recorrentes com base no artigo $8^{\circ}$ (EUROPA,

para garantir-lhe a potabilidade é um atentado a esse direito, conforme Kolyadenko e Outros v. Rússia, de 28/02/2012 (EUROPA, 2016, p. 22).

8 "[T]he very strong combination of indirect evidence and presumptions makes it possible to conclude that the applicant's health deteriorated as a result of her prolonged exposure to the industrial emissions from the Severstal steel plant. Even assuming that the pollution did not cause any quantifiable harm to her health, it inevitably made the applicant more vulnerable to various illnesses. 
1998a). Dois juízes manifestaram-se no sentido de também ser reconhecida a violação ao direito à vida. Um deles, o juiz Jambrek, escreveu, em seu voto concorrente, que a proteção à saúde e à integridade física é intimamente associada tanto com o "direito à vida" quanto com o "respeito à vida privada e familiar".

Na prática, o direito à vida atua como uma cláusula reserva de proteção ao meio ambiente, sempre que atividade ou dano ao ambiente tiverem importado vítimas fatais, como em Öneryildiz v Turquia, ou, também em situações limites de grave risco à vida, não houver clara incidência do direito ao respeito à vida privada e familiar (KRAVCHENKO; BONINE, 2012, p. 280-281). Essa derradeira orientação, no entanto, ainda não foi desafiada claramente na jurisprudência, podendo-se identificar uma quantidade razoável de casos, como se verá no próximo item, em que não se reconheceu a violação, mesmo diante de potenciais riscos à saúde e à vida. É, no entanto, uma oportunidade de evolução jurisprudencial, a seguir-se a tendência de proteger o meio ambiente sob abrigo de disposições expressas da Convenção.

Um direito como limite à atividade econômica e ao direito propriedade

Algumas decisões da Corte Europeia de Direitos Humanos protegem o meio ambiente como instrumento de política pública que, justificado por um interesse público, coletivo ou geral, importe restrição a outros direitos. A proteção (ou um direito ao meio ambiente equilibrado) decorreria do juízo de conveniência do Estado para adotar medidas restritivas, desde que, autorizadas por lei, pudessem ser consideradas adequadas e necessárias numa sociedade democrática à persecução desse fim. E se tornaria visível no repertório jurisprudencial pelo questionamento dos titulares dos direitos restringidos perante a Corte. A proteção e o direito, numa primeira mirada, já se mostrariam um interesse legítimo e capaz de superar outros direitos, notadamente a propriedade, a liberdade econômica e até mesmo, como se viu, o direito ao respeito da vida privada e familiar. Mas, segundo a orientação da Corte, haveria de, como uma ingerência estatal, passar no filtro da proporcionalidade ou do justo equilíbrio entre os interesses em concorrência (MCHARG, 1999).

Em Fredin v. Suécia (EUROPA, 1991), a Corte reconheceu a prevalência do interesse público de proteção ambiental para restringir o direito de propriedade. Fredin e sua esposa alegavam que a revogação da licença de exploração de um poço de cascalho constituía uma privação do seu direito de propriedade. Embora reconhecesse que a revogação, sem a devida indenização, reduzisse a capacidade de exploração dos recursos da propriedade, a Corte considerou-a legítima, por impor o uso mais racional da propriedade, de acordo com o interesse geral de proteção ambiental ${ }^{9}$, sem, por outro lado, esvaziar o conteúdo do direito de propriedade. Em Pine Valley Developments Ltd e outros v. Irlanda (EUROPA, 1991b), a Corte também considerou legítima a

Moreover, there can be no doubt that it adversely affected her quality of life at home".

9 "The Court recognises for its part that in today's society the protection of the environment is an increasingly important vol.10, nº. 02, Rio de Janeiro, 2017.pp. 779-800 
anulação de permissão de construção, baseada na legislação urbanística destinada a proteger o meio ambiente, ainda que aprovada supervenientemente e, por conseguinte, frustrando os planos de exploração do terreno adquirido para esse $\operatorname{fim}^{10}$. Por igual, em Hamer v. Bélgica, afirmou-se que era legítima a ordem de demolição de uma casa, construída quase trina anos antes, por haver violação dos regulamentos florestais e da exigência de prévia autorização de construção. Afirmou-se que os imperativos financeiros e até mesmo certos direitos fundamentais, tais como a propriedade, não poderiam ter prevalência sobre a proteção ambiental, em especial quando o Estado tiver legislado sobre o assunto, promovendo adequado balanço entre os interesses em conflito (EUROPA, 2008, \$ 79). A mesma orientação foi seguida em Depalle v. França e Brosset-Triboulet v. França, julgados em 29/03/2010. Tratava-se de impugnação de ordens de demolição, às próprias custas e sem compensação, de casas e outras benfeitorias construídas, há muito tempo, em terrenos de marinha com as devidas autorizações obtidas. Uma legislação superveniente de proteção das zonas costeiras impedia a renovação das autorizações, obrigando a desocupação da área e demolição das obras realizadas. A Corte entendeu legítima a exigência, sob o fundamento de que a política de conservação ambiental era de interesse geral da comunidade, sobrepondo-se aos direitos dos requerentes (EUROPA, 2010b; 2016, p. 25).

Entretanto, em Papastavrou v. Grécia, entendeu-se que a obrigatoriedade de recomposição do ambiente, por meio de reflorestamento, sem levar em conta as condições do solo e o quadro que se vinha agravando desde muito tempo, violava o direito de propriedade, assegurado pelo artigo 1. ${ }^{\circ}$ do Protocolo n. 1 da Convenção. Faltara ao Estado o estabelecimento de um equilíbrio razoável entre o interesse público da recuperação ambiental e as exigências da proteção dos direitos dos recorrentes (EUROPA, 2003b). Assim também, disse, em Turgut v. Turquia, julgado em 08/07/2008, que a desapropriação de terras sem a devida indenização, ainda que sob fundamento de que se destinavam à proteção de florestas nacionais, violava o mesmo direito (EUROPA, 2016, p. 25).

\section{A proteção reflexa da dimensão processual do direito a o a mbiente equilibrado}

Em diversos casos, a Corte pronunciou-se pela violação dos direitos ambientais processuais, valendo-se de dispositivos da Convenção que lhes dizem respeito, associados, quase sempre, a direitos substantivos. A informação ambiental é derivação do direito ao acesso à informação, garantido pelo artigo 10; o acesso à Justiça,

consideration" ( $\$ 48)$.

10 "The applicants did not dispute that the interference was in conformity with planning legislation and, like that legislation, was designed to protect the environment (see paragraph 9 above). This, in the Court's view, is clearly a legitimate aim "in accordance with the general interest" for the purposes of the second paragraph of Article 1" (\$ 57). Em Valico S.R.L.v. Itália, 21/03/ 2006, não foi admitido o recurso de uma empresa que fora multada por violar as regras de construção de edificios, destinadas a proteger a paisagem e o ambiente. A Corte observou que a medida tinha fundamento legal e perseguia objetivo legítimo de preservação da paisagem e de garantia de um planejamento racional e ambientalmente saudável (EUROPA, 2016, p. 24). 
em casos ambientais, é extraído do processo equitativo e da tutela judicial efetiva (arts. 6 e 13). Essas violações são, em regra, conjugadas com atentados à vida privada e familiar. Afirma-se que a dimensão processual desse direito, embora não seja expresso no artigo $8^{\circ}$, é uma decorrência necessária de sua efetividade, pois todo processo decisório que venha impactá-lo deve respeitar as exigências de informação, participação e, se for o caso, acesso às cortes (EUROPA, 2006, \$\$ 82-83) ${ }^{11}$.

Em Guerra v. Itália (1998a), por exemplo, as autoridades públicas tinham violado o artigo $10 \mathrm{da}$ Convenção, por não fornecerem informação necessária sobre o escapamento de produtos químicos de uma fábrica em Manfredônia. Em Tătar v. Romênia (2009c), o Estado não cumprira com seu dever de informar a população sobre os riscos de instalação de uma mina de ouro que veio a contaminar o Rio Sasar. Em Vilnes v. Noruega (EUROPA, 2013), por igual, houve falha das autoridades norueguesas em informar aos trabalhadores de empresas de petróleo sobre os riscos de mergulhos em águas profundas do Mar do Norte. Em Öneryildiz v. Turquia (2002), o Estado não fornecera proteção judicial efetiva às vítimas de uma explosão de gás metano num aterro sanitário. Em todos eles, atentou-se contra a dimensão processual do direito ao respeito à vida privada e familiar dos reclamantes.

Embora, em Hatton v. Reino Unido, de 8 de julho de 2003, como se viu, os autores tenham perdido a demanda sobre a violação do artigo $8^{\circ}$, tendo o Plenário (Grande Seção) da Corte revertido, em revisão pedida pelo Reino Unido, a decisão tomada pela Terceira Seção, em 2 de outubro de 2001, dois pontos merecem atenção no caso (EUROPA, 2003d). A utilização, pela primeira vez, da expressão "direitos humanos ambientais" no âmbito daquele órgão (2003d, $\$ 122$ ); e, mais importante, a vinculação que, nas argumentações, foi feita entre o estudo de impacto ambiental e os direitos ambientais, tanto no julgado de 2001 (EUROPA, 2001e, \$ 106), quanto no de 2003 (EUROPA, \$S 104, 128).

A jurisprudência que se formou em torno do assunto exige que os Estados realizem ou determinem que sejam realizados prévios estudos de impacto ambiental nos processos de decisão de viabilidade social, humana e ambiental de atividades que possam causar sérias consequências ao ambiente e à saúde das pessoas, havendo de ponderar os interesses em conflito de modo fundamentado, como se argumentou, num resumo da compreensão dada pela Corte ao assunto, em Giacomelliv. Itália (EUROPA, 2006b, \$ 83-87) e foi reiterado em Grimkovskaya v. Ucrânia (EUROPA, 2011d). Tais estudos devem ser transparentes, de modo a permitirem a participação (ou, no mínimo, questionamentos) dos interessados (EUROPA, 2006b, \$94).

Caso os comentários e críticas feitos pelos interessados não forem levados em conta no processo decisório, eles podem recorrer ao Judiciário nacional e, em última instância, à própria Corte, como foi

\footnotetext{
11 "It reiterates that it has consistently held that although Article 8 contains no explicit procedural requirements, the decisionmaking process leading to measures of interference must be fair and must afford due respect to the interests safeguarded to the individual by Article 8"
} 
reconhecido expressamente em Taşkin v. Turquia (EUROPA, 2004a, \$ 119). A conclusão do EIA no sentido de que a atividade compromete seriamente o meio ambiente e a saúde das pessoas, num eventual licenciamento corretivo, por exemplo, exige que o Estado lhe determine a imediata suspensão. Foi o que decidiu em Giacomelli v. Itália (EUROPA, 2006, \$92).

A "crise do lixo" na Itália também merece ser citada aqui. Entre outras violações, os requerentes afirmavam que não haviam recebido do Estado informação adequada sobre os perigos causados por um ambiente insalubre. A Corte reiterou a necessidade de, conforme o artigo $8^{\circ}$ da Convenção, as pessoas receberem informações das autoridades públicas que as possibilitassem avaliar adequadamente os riscos que corriam, embora tenha considerado que houve cumprimento desse dever, em virtude da publicação dos estudos encomendados pelo governo sobre o assunto. Entretanto, considerou inadequado o acesso à Justiça permitido às vítimas, pois, de acordo com a legislação italiana, elas teriam que provocar o Ministro do Meio Ambiente para que encaminhasse seus pleitos indenizatórios às autoridades judiciárias, contrariando os artigos convencionais $6^{\circ}$ e 13 (acesso à Justiça) e 35.1 (acesso à Corte segundo o princípio da subsidiariedade), que exigem mais que uma garantia abstrata de um direito de ação, um remédio judicial efetivo.

$\mathrm{O}$ acesso ao Judiciário é uma das garantias caras aos direitos ambientais de caráter processual. $\mathrm{O}$ artigo convencional 6.1 reconhece a todos o direito a que a sua causa seja examinada, equitativa e publicamente, num prazo razoável por um tribunal independente e imparcial, estabelecido pela lei. Em Zander v. Suécia, a Corte afirmou que a negativa da Justiça local de rever uma decisão administrativa que concedera renovação de licença a uma empresa, responsável pela poluição da água que abastecia a comunidade, violava referido artigo convencional $\left(\right.$ EUROPA, 1993) ${ }^{12}$. Nem o Judiciário nem a legislação podem privar as pessoas de recorrerem aos tribunais contra qualquer decisão, ato ou omissão em que considerem que os seus interesses ou seus comentários não tiveram suficiente peso no processo de tomada de decisão, afirmou a Corte em Taşkin v. Turquia (EUROPA, 2004a, \$ 1 19). A legitimidade de associações e entidades deve ser reconhecida pelas legislações nacionais, embora esse controle não seja tão efetivo, pois, para acesso à própria Corte Europeia, exige-se a defesa de interesses concretos, não havendo como discutir eventual inexistência de legitimidade ativa extraordinária ou de interesse coletivo e abstrato por parte de tais associações e entidades (EUROPA, 2009d). Por outro lado, a Corte tem enfatizado a necessidade de que a resposta do Judiciário seja, o mais possível, rápida. A demora é uma forma transversa de negar jurisdição, como afirmou em Dee\s v. Hungria, de 09/11/2010, e Bor v. Hungria, de 18/06/ 2013 (EUROPA, 2016, p. 15, 18).

Há, na garantia de acesso à Justiça, um dever de os juízes realizarem um fundamentado juízo de adequação ou ponderação entre os direitos e interesses em conflito, não bastando apelos retóricos ou argumentos

\footnotetext{
${ }^{12}$ Vejam-se também Kolyadenko and Others v. Rússia, de 28/02/2012 (EUROPA, 2016, p. 22).
} 
baseados em testes formais que, na prática, conferem ampla deferença à decisão do poder público (EUROPA, 2003d, $\$ 141 ; 2011$ d). Assim também, o estabelecimento de prazos prescricionais para ações reparatórias, em situações de exposição a substâncias tôxicas, deve ser analisado com prudência, pois as consequências, de regra, só aparecerão tardiamente. Em Howald Moor v. Suiç̧a, entendeu-se que a definição do lapso prescricional de 10 anos a contar da exposição ao amianto, independentemente do tempo de conhecimento da manifestação da doença, por ele, provocada, violava o direito ao acesso à Justiça e ao processo equitativo, previsto no artigo convencional $6^{\circ}$ (EUROPA, 2014b).

A proteção judicial efetiva requer, mais do que acesso à Justiça, um processo justo e uma decisão fundamentada, o efetivo cumprimento das decisões judiciais, quando transitarem em julgado. A falta ou inefetividade de providências estatais para cumprir a ordem judicial de reparação do dano ambiental, seja no sentido da demolição de obras que o provocavam, como disse a Corte em Kyrtatos v. Grécia (EUROPA, 2003), seja para suspender a atividade de uma fábrica altamente poluente, como em Giacomelli v. Itália (EUROPA, 2006) e Apanasewicz v. Polônia (EUROPA, 2011c), ou de um cemitério construído sem atender aos requerimentos ambientais, em Dzemyuk v. Ucrânia (EUROPA, 2014), viola o Estado de direito.

A Corte, em diversas ocasiões, considerou ainda atentatória a essa garantia a aprovação de leis destinadas a influenciar o resultado de um processo, sobretudo quando o Estado for parte e já tenha havido, mesmo sem trânsito em julgado, um exame do mérito (v.g., 1994b; 1997b; 1999; 2003b). Em Gorraiz Lizarraga e Outros v. Espanha, de 2004, a Corte reafirmou que, embora o legislador não esteja impedido de adotar novas disposições retrospectivas para regular direitos decorrentes de leis existentes, o princípio do Estado de direito e da noção de processo equitativo, consagrado no artigo $6^{\circ}$, impediria que o fizesse para alterar ou, de outro modo, interferir no resultado da decisão judicial (EUROPA, 2004b, \$ 64).

Não viu problema, no entanto, em lei aprovada pela Comunidade Autónoma de Navarra que, posteriormente à decisão da Suprema Corte do país que cancelara a autorização para construção de uma barragem causadora de graves danos ao meio ambiente, permitiu que nova licença fosse dada à construção, ao reclassificar as zonas de proteção ambiental e a atividades permitidas dentro delas. Segundo Estrasburgo, a lei contestada disciplinava todas as reservas e sítios naturais protegidos de Navarra, e não apenas a área afetada pela construção do reservatório.

\section{PROBLEMAS E ALTERNATIVAS DA PROTEÇÃO REFLEXA}

O emprego da intepretação extensiva nem sempre é muito efetiva, dadas as exigências que traz consigo, notadamente a de que seja demonstrado um dano direto, imediato ou iminente. Não basta, como visto, o mero risco à saúde como, por exemplo, uma eventual ou suposta exposição à radiação nuclear pela proximidade do local 
onde se realizariam testes atômicos (EUROPA, 1995), de uma estação de energia nuclear (EUROPA, 1997), da linha de ferro, por onde seriam transportados seus resíduos (EUROPA, 1996a) ou, ainda, pelo acometimento de leucemia em decorrência dessa exposição, sem prova de relação causal direta ou dos prejuízos à saúde (EUROPA, 1998c).

Se houver um grau de incerteza razoável, não haverá proteção. Essa questão de prova se relaciona com a necessidade de que o postulante seja uma "vítima potencial" ou uma pessoa lesada pelo ato omissivo ou comissivo impugnado, não havendo possibilidade de "actio popularis" ou de uma ação coletiva com legitimado ativo a discutir um direito que não o tenha afetado. É a leitura restritiva que se dá ao artigo 34 da Convenção, a dizer que a Corte pode receber petições de qualquer pessoa singular, organização não governamental ou grupo de particulares que se considere vítima de violação pelos Estados dos direitos reconhecidos na Convenção ou nos seus protocolos (EUROPA, 2007b).

Assim também, não é qualquer interferência na vida privada e familiar que leva ao provimento da demanda. A instalação de um transformador ao lado de uma residência, por mais que traga certo grau de ruído e de desconforto por suas vibrações, evitando até mesmo a utilização de parte do imóvel, não viola a vida privada e familiar dos moradores, pois a instalação seria suficientemente justificada com base na melhoria do fornecimento de energia elétrica que traria para toda a cidade (EUROPA, 2012) ${ }^{13}$. Essa orientação já se havia prenunciado na revisão, pela Corte plena, no caso Hatton e outros v. Reino Unido em 2003 (EUROPA, 2003d). O Estado havia realizado "um justo equilíbrio" entre os interesses econômicos, com a ampliação dos voos noturnos em Heathrow, e os direitos das pessoas afetadas pelo aumento do barulho dos aviões. As questões ambientais não eram o ponto definitivo para decidir-se o conflito, senão um dos interesses em jogo, sequer podendo dar-lhe, diretamente, o status de direitos humanos:

A proteção do ambiente deve ser levada em consideração pelos Estados, dentro de sua margem de apreciação [do conflito de interesses], e pela Corte, no controle que faz dessa margem, mas não seria adequado que a Corte adotasse uma abordagem especial a esse respeito, [atribuindo-a] um estatuto especial de direitos humanos ambientais $(\$ 225)^{14}$.

Tampouco se reconheceu ter havido atentado contra o direito ao respeito da vida privada e familiar dos donos de uma casa nas proximidades de uma área úmida, que servia como uma espécie de santuário para alguns pássaros e outras espécies, pela mudança na legislação urbanística que permitirá a construção de prédios naquela

\footnotetext{
${ }^{13}$ Embora reconhecendo a possibilidade de contaminação eletromagnética, a Corte não admitiu outras demandas como Luginbühl v. Suiça, de 17/01/2006; e Hans Gaida v. Alemanha, de 03/07/2007a.

14 "Environmental protection should be taken into consideration by States in acting within their margin of appreciation and by the Court in its review of that margin, but it would not be appropriate for the Court to adopt a special approach in this respect by reference to a special status of environmental human rights". (EUROPA, 2003d). Também sobre barulho provocado por aeroporto: Flamenbaum and Others v. France; de 13/12/2012. No mesmo sentido da tolerabilidade do som produzido por fogos de artifício, em Zammit Maempel and Others v. Malta, de 22/11/201 1, ou daqueles causados por bares nas imediações da casa do reclamante, em Chiş v. Romania, de 09/09 2014 (EUROPA, 2016, p. 15-16). Sobre emissão de gases poluentes: Greenpeace e.V. and Others v. Germany, de 12/05/2009 (EUROPA, 2016, p. 18).
} 
área, o que, certamente, impactaria negativamente o ambiente (EUROPA, 2003a). O curioso desse caso, é que o Judiciário local os havia dado razão, baseando-se no direito ao meio ambiente equilibrado. O descumprimento da decisão é que motivara a submissão do assunto à Corte Europeia. Ela, porém, não fora sensível à consideração de que, além da possível mudança da paisagem no entorno da casa dos requerentes, a própria destruição do santuário ecológico afetaria o bem-estar de seus moradores. Era preciso um dano ambiental maior, disse a Corte, para abalar a capacidade de desfrute da vida privada e familiar, a ponto de autorizar sua intervenção:

Poderia ser diferente, se, por exemplo, a deterioração ambiental denunciada consistisse na destruição de uma área florestal nas imediações da casa dos recorrentes, uma situação que poderia afetar mais diretamente o seu bem-estar (EUROPA, 2003a, \$269). ${ }^{15}$

Como se nota, o sucesso da demanda depende da gravidade e da evidência do dano ambiental associado à seriedade da violação de um direito reconhecido pela Convenção. Em López Ostra, a Corte reconheceu que a poluição ambiental era grave o bastante para tornar insuportável a vida privada e familiar. Nem sempre é, entretanto, previsível, quanto será considerado grave ou tolerável um dano. Aspectos do conteúdo processual do direito podem convencer os juízes. A falha em prestar informações sobre os riscos de uma atividade, por exemplo, pode ser o argumento decisivo (EUROPA, 1998a). Quando há atentado às próprias leis ambientais do país, aumentam-se também as chances de convencimento, avaliando-se que o Estado não realizou um justo equilíbrio entre o interesse geral e o direito ao respeito à vida privada (BOYLE, 2007, p. 489). Em Fadeyeva v. Rússia, por exemplo, a Corte reconheceu que "a violação do direito interno, nesses casos, poderia levar necessariamente à constatação de uma violação da Convenção." (EUROPA, 2005, \$95) ${ }^{16}$. O mesmo argumento foi empregado em Dzemyuk v. Ucrânia (EUROPA, 2014), dentre outros tantos casos.

A falta de reconhecimento expresso do direito torna a previsão de sucesso das demandas uma tarefa complicada, por mais que se tentem extrair da jurisprudência razões de afirmação ou recusa das demandas. Serão sempre razões para probabilidades. A relação entre proteção ao ambiente e a de grupos vulneráveis só confirma essa indefinição. Ambas se podem conjugar, mas também entrar em conflito. A ocupação há muito tempo de uma área de importante valor ambiental, por um grupo de pessoas socialmente vulneráveis, não autoriza a remoção forçada, sob pena de atentado à inviolabilidade do domicílio (EUROPA, 2014a). Como se viu, porém, em diversos casos envolvendo o Reino Unido, a Corte considerou legítima a retirada de ciganos que se instalaram, sem licença, numa área sujeita a restrições com o objetivo de proteção ambiental (EUROPA, 1996b; 2001a, b, c, d; 2003c).

\footnotetext{
15 "It might have been otherwise if, for instance, the environmental deterioration complained of had consisted in the destruction of a forest area in the vicinity of the applicants' house, a situation which could have affected more directly the applicants' own wellbeing".

16 "The breach of domestic law in these cases would necessarily lead to a finding of a violation of the Convention".
} 
O fenômeno da "ecologização" da Convenção Europeia, mesmo com as deficiências apontadas, tem evoluído aos poucos para uma espécie de "abstração" da proteção reflexa do direito ao respeito da vida privada e familiar. Há quem defenda, na falta de um direito expresso, a substituição ou complementação da proteção indireta pela doutrina do interesse geral que, baseada na Convenção e jurisprudência da Corte, poderia superar os obstáculos de se ter de demonstrar o vínculo subjetivo entre o dano ambiental e a violação do direito de quem postula. Haveria um interesse geral de defesa e salvaguarda do meio ambiente como um bem e responsabilidade de todos. Associado ao princípio da precaução, ter-se-ia um argumento adequado para prevenir-se ou reparar-se um dano (ARIÑO, 2015).

De fato, a jurisprudência da Corte se tem valido da noção de interesse geral como elemento argumentativo para avaliar se determinadas ingerências do Estado no âmbito privado são legítimas e proporcionais, inclusive, como se viu, na questão ambiental. É questionável, inclusive teoricamente, que o direito ao meio ambiente equilibrado seja visto sob o ângulo antipático de um mero limite a direitos, um direito a limite de direitos, por assim dizer. Depois, como se viram, casos como Powell y Rayner v. Reino Unido foram decididos a favor de outros interesses gerais em detrimento do meio ambiente, o que mostra também a incerteza quanto à orientação a ser adotada pela Corte (MCHARG, 1999).

Como estratégia de superar o obstáculo processual da doutrina da vítima potencial, pode ser útil como argumento adicional, não como elemento substitutivo. Parece mais acertado que, na falta de um reconhecimento expresso, continue-se, primariamente, a adotar a doutrina da proteção indireta ou reflexa, de rebote, por meio da qual, o direito ao meio ambiente equilibrado aos poucos ganha espaço mais vivo, mesmo que sob o guarda-chuva do artigo $8^{\circ}$.

\section{CONSIDERAÇÕES FINAIS}

A Corte Europeia de Direitos Humanos não tem reconhecido, na $\mathrm{CEDH}$, a existência de um direito ao meio ambiente equilibrado implícito. Os esforços políticos para torná-lo expresso têm sido, até agora, vãos. Isso não significa, porém, que não haja uma série de normas e políticas destinadas a promover em toda Europa uma proteção ambiental. Tampouco importa dizer que a Corte seja insensível à questão.

Os juízes de Estrasburgo se têm valido do reconhecimento de direitos expressamente previstos na Convenção para afirmar, de modo reflexo, a proteção daquele direito. Especialmente o direito ao respeito à vida privada e familiar, assegurado pelo artigo $8^{\circ}$, e, em menor escala, o direito à vida, afirmado pelo artigo $2^{\circ}$, têm servido a esse propósito. Há ainda decisões que conferem a referida proteção, considerando-a um interesse da comunidade que se impõe, segundo um juízo de proporcionalidade, sobre direitos individuais, principalmente, a propriedade. 
Essa doutrina tem reconhecido não apenas um dever estatal de não causar dano ambiental, mas também uma obrigação de evitar que se faça e de punir quem o faça, reparando as vítimas pela degradação produzida. Por se tratar de uma proteção reflexa ou indireta, ela tem suas limitações. Em primeiro lugar, exige-se que seja demonstrado um dano direto, imediato ou iminente, por quem alega, o que nem sempre (ou quase nunca) é tarefa muito fácil, em se tratando do tipo de dano em causa. Assim também, não é qualquer interferência na vida privada e familiar que leva ao provimento da demanda. Nem é qualquer alegação de que uma certa atividade que cause dano ao meio ambiente provoque risco à vida dos demandantes. Há uma exigência de gravidade que torna complicada a previsão do entendimento que será exposto. Em benefício da atividade, normalmente, de conteúdo econômico; ou do meio ambiente, travestido, de atentado à vida privada e familiar ou à vida, simplesmente.

De toda sorte, a evolução da jurisprudência da Corte tem revelado um certo "descolamento", uma "abstração" do direito diretamente invocado para tutelar o direito indiretamente protegido. Essa evolução se não permite prognosticar que Estrasburgo venha, amanhã, a reconhecer um direito ao meio ambiente equilibrado implícito na Convenção Europeia, autoriza afirmar que cada vez mais conteúdo desse direito será abrangido pela proteção deferida.

O grande prestígio de Estrasburgo tende a neutralizar os poucos ruídos que ainda existem em face dos tribunais e dos poderes políticos dos Estados. E é esse prestígio que, por meio do aprofundamento da "ecologização" dos direitos da Convenção Europeia, ajudará a ampliar o consenso em torno da necessidade de afirmação de um direito ao meio ambiente equilibrado. Um "paradoxo de proteção" a favor do verde. A história nem sempre encontra o caminho mais curto entre dois pontos. Mas é a história que vale. Nem tanto a que se conta, mas a que se vive a contar e fazer.

\title{
THE “GREENING" OF THE EUROPEAN CONVENTION ON HUMAN RIGHTS: VICES AND VIRTUES
}

\begin{abstract}
There is no express right to a balanced environment in the European Convention on Human Rights (ECHR). Nevertheless, there are several rules and policies to promote the environmental protection throughout Europe. Although not recognizing it as an implicit right in the ECHR, the European Court of Human Rights has been making use of the rights provided therein, particularly the right to respect for private and family life, to affirm it reflexively. It is what has been called "greening" of the European Convention. This understanding presents its problems, but it has been an instrument that progressively extends the protection of that right, both in its substantive aspect, and in its procedural dimension.
\end{abstract}

Keywords: European Court of Human Rights. Right to a balanced environment. Greening the European Convention on Human Rights. Human Rights. Environmental Law. 


\section{REFERENCIAS}

ARIÑO, Omar B. Tribunal Europeo de Derechos Humanos: La Protección Ambiental entre el Interés General y los Derechos Individuales. In RAMÓN, Fernando L.; GARCÍA, José Francisco A. (coord.). Observatorio de Políticas Ambientales. Pamplona: Thompson/Aranzani, p. 141-168, 2015.

BOYLE, Alan. Human Rights or Environmental Rights? A Reassessment. Fordham Environmental Law Review, v 18, p. 471-511, 2007.

DOMÍNGUEZ, Judith. El Funcionamiento del Sistema de Protección Ambiental de la Unión Europea: Principios, Instituciones, Instrumentos. Estudios Demográficos y Urbanos, v. 22, n. 3, p. 689-715.

ESPANHA. Tribunal Constitucional, sent. 16/2004, de 23/02/2004. Disponível em: <http://zip.net/bptqwd>. Acesso em: 22 jul. 2016.

Tribunal Constitucional. Sala Primeira. Sent. 16/2004, de 23/02/2004. Recurso de amparo 1784/1999. Disponível em: <http://zip.net/bttqLP>. Acesso em: 22 jul. 2016.

Tribunal Supremo. Sala de lo Contencioso, STS 4967/2002. Disponível em: <http://zip.net/bvtqgJ>. Acesso em: 22 jul. 2016.

Comissão de Ministros. CM/AS(2010)Rec1883-1885 final, 18/06/2010a. Disponível em: <http://zip.net/bntqgQ>. Acesso em: 22 jul. 2016.

Comissão de Ministros. Supervision of the Execution of Judgments of the ECHR First Annual Report, 2007c. Strasbourg, 2008. Disponível em : <http://zip.net/bmtqdf>. Acesso em: 14 mai. 2016.

Comissão de Ministros. Supervision of the Execution of Judgments of the ECHR. First Annual Report, 2015. Strasbourg, 2016. Disponível em: <http://zip.net/brtp5W>. Acesso em: 14 jun. 2016.

Comissão Europeia de Direitos Humanos. L, M \& R v.Switzerland, de 01/07/1996a, App. No. 30003/96. EHRR 1996, 3, 801.

Comissão Europeia de Direitos Humanos. Noel Narvii Tauira and Eighteen others v. France, de 04/12/1995. Disponível em: <http://zip.net/bytqwL>. Acesso em: 11 mai. 2016.

Convenção Europeia de Direitos Humanos de 1950. Disponível em: <http://zip.net/brtpT2>. Acesso em: 11 fev. 2016.

Corte Europeia de Direitos Humanos. Balmer-Schafroth and Others v. Switzerland, de 20/08/1997a. Disponível em: <http://zip.net/bltpwP>. Acesso em: 11 mai. 2016.

Corte Europeia de Direitos Humanos. Apanasewicz v. Poland, de 03/05/2011c. Disponível em:<http://zip.net/bgtp2s>. Acesso em: 22 jul. 2016.

Corte Europeia de Direitos Humanos. Atanasov v Bulgaria, de 11/04/2011b. Disponível em: <http://zip.net/bptqMT>. Acesso em: 11 fev. 2016.

Corte Europeia de Direitos Humanos. Beard v. the United Kingdom, de 18/01/2001a. Disponível em: <http://zip.net/bdtql2>. Acesso em: 11 mai. 2016.

Corte Europeia de Direitos Humanos. Brânduse v. Romania, de 07/04/2009e. Disponível em:<http://zip.net/bttqTH>. Acesso em: 11 fev. 2015.

Corte Europeia de Direitos Humanos. Brincat and Others v. Malta, de 24/07/2015. Disponível em: <http://zip.net/bqtq7z>. Acesso em: 22 jul. 2016.

Corte Europeia de Direitos Humanos. Brosset-Triboulet and Others v. France, 29/03/2010b. Disponível em:<http://zip.net/bhtqjS >. Acesso em: 11 fev. 2015.

Corte Europeia de Direitos Humanos. Buckleyv. the United Kingdom, de 26/08/1996b. Disponível em: <http://zip.net/bptqtW>. Acesso em: 11 mai. 2016.

Corte Europeia de Direitos Humanos. Chapman v. the United Kingdom, de 18/01/2001b. Disponível em: <http://zip.net/bptqtY>. Acesso em: 11 mai. 2016. 
Corte Europeia de Direitos Humanos. Coster v. the United Kingdom, de 18/01/2001c. Disponível em: $\overline{<h t t p: / / z i p . n e t / b u t q f p>. ~ A c e s s o ~ e m: ~} 11$ mai. 2016.

Corte Europeia de Direitos Humanos. Dubetska and Others v. Ukraine, de 10/05/2011a. Disponível em: <http://zip.net/bjtpXg $>$. Acesso em: 11 fev.2016.

Corte Europeia de Direitos Humanos. Dzemyuk v. Ukranie, 04/12/ 2014. Disponível em: <http://zip.net/bstqn9>. Acesso em: 11 fev. 2016.

Corte Europeia de Direitos Humanos. Environment and the Convention on Human Rights. Strasbourg:

ECHR/Press Unit, june 2016. Disponível em: <http://zip.net/bstqhX>. Acesso em: 16 jul. 2016.

Corte Europeia de Direitos Humanos. Ezeh and Connors v. the United Kingdom, de 9/10/2003c.

Disponível em: <http://zip.net/bxtqPL >. Acesso em: 11 fev. 2016.

Corte Europeia de Direitos Humanos. Fadeyeva v. Russia, de 30/11/2005. Disponível em: <http://zip.net/bhtp6J>. Acesso em: 11 fev. 2016.

Corte Europeia de Direitos Humanos. Fredin v. Sweden, 18/02/1991a. Disponível em: <http://zip.net/bptqtD>.Acesso em: 11 mai. 2016.

Corte Europeia de Direitos Humanos. Gestoras Pro-Amnistia y Otros v. Consejo de la Unión Europea, de 27/02/2007b. Disponível em: <http://zip.net/bxtq2c>. Acesso em: 11 mai. 2016.

Corte Europeia de Direitos Humanos. Giacomelli v. Italy, de 02/11/2006b. Disponível em: $<$ http://zip.net/bvtqnv>. Acesso em: 11 mai. 2016.

Corte Europeia de Direitos Humanos. Gorraiz Lizarraga and Others v. Spain, de 10/11/2004b. Disponível em: <http://zip.net/bytqhQ>. Acesso em: 11 mai. 2016.

Corte Europeia de Direitos Humanos. Grimkovskaya v. Ukraine, de 21/07/ 2011d. Disponível em: <http://zip.net/bdtqGg>. Acesso em: 22 jul. 2016.

Corte Europeia de Direitos Humanos. Guerra and Others v. Italyde 19/02/1998a. Disponível em: $\overline{<h t t p: / / z i p . n e t / b k t p 4 s>. ~ A c e s s o ~ e m: ~} 11$ mai. 2016.

Corte Europeia de Direitos Humanos. Hamer v. Belgium, 27/02/2008. Disponível em: <http://zip.net/bvtqzJ>. Acesso em: 11 fev. 2016.

Corte Europeia de Direitos Humanos. Hans Gaida v. Germany, de 03/07/2007a. Disponível em: <http://zip.net/bqtq2V>. Acesso em: 12 mai. 2016.

Corte Europeia de Direitos Humanos. Hardy Maile v. United kingdom de 09/07/2012. Disponível em: <http://zip.net/bqtq2L >.Acesso em: 11 mai. 2016.

Corte Europeia de Direitos Humanos. Hatton and Others v. United Kingdom (Third Section), de 02/10/2001e. Disponível em: <http://zip.net/bdtqFt>. Acesso em: 11 fev. 2016.

Corte Europeia de Direitos Humanos. Hatton and Others v. United Kingdom (Grand Section), de 8/07/2003d. Disponível em: <http://zip.net/bktpXg>. Acesso em: 11 fev. 2016.

Corte Europeia de Direitos Humanos. Howald Moor v. Switzerland, de 11/06/2014b. Disponível em: <http://zip.net/bptqLL>. Acesso em: 12 mai. 2016.

Corte Europeia de Direitos Humanos. Kyrtatos v. Greece, de 22/08/2003a. Disponível em: <http://zip.net/bntpZr>. Aceso em: 11 mai. 2016.

Corte Europeia de Direitos Humanos. L’Erablie囚re asbl v. Belgium, de 24/02/2009d. Disponível em:<http://zip.net/bxtq7b>. Acesso em: 11 fev.2015.

Corte Europeia de Direitos Humanos. LCB v. United Kingdom, de 09/06/1998c. Disponível em: <http://zip.net/bqtq2R >. Acesso em: 11 mai. 2016.

Corte Europeia de Direitos Humanos. Lee y Jane Smith v. the United Kingdom, de 18/01/2001d. Disponível em: <http://zip.net/bytqh7>. Acesso em: 11 mai. 2016.

Corte Europeia de Direitos Humanos. López Ostra v. Spain, de 09/12/1994a. Disponível em: <http://zip.net/bktqc9>.Acesso em: 14 fev. 2016.

Corte Europeia de Direitos Humanos. Luginbühl v switzerland, de 17/01/2006a. Disponível em: $<$ http://zip.net/bftpZr>. Acesso em: 11 mai. 2016. 
Corte Europeia de Direitos Humanos. McGinley and Egan v. United kingdom, de 09/06/1998b. Disponível em: <http://zip.net/bdtqzd >. Acesso em: 11 mai. 2016.

Corte Europeia de Direitos Humanos. Moreno Gómez v. Spain, de 16/11/2004c. Disponível em: <http://zip.net/bxtqMY>. Acesso em: 14 fev. 2016.

Corte Europeia de Direitos Humanos. National \& Provincial Building Society, Leeds Permanent Building Society e Yorkshire Building Society ( "Building Societies") v. Reino Unido, de 23/10/1997b. Disponível em: <http://zip.net/brtpVq>. Acesso em: 11 mai. 2016.

Corte Europeia de Direitos Humanos. Papageorgiou v. Greece, de 9/08/2003b. Disponível em: <http://zip.net/bttqxq>. Acesso em: 11 mai. 2016.

Corte Europeia de Direitos Humanos. Pine Valley Developments Ltd and others v. Irland, 29/11/1991b. Disponível em: <http://zip.net/bqtqN9>. Aceso em: 11 mai. 2016.

Corte Europeia de Direitos Humanos. Powell y Rayner v. the United Kingdom, de 21/02/1990. Disponível em: <http://zip.net/bytqjb>. Acesso em: 11 fev. 2016.

Corte Europeia de Direitos Humanos. Roche v. United kingdom, de 19/10/2005. Disponível em: <http://zip.net/bstqhR>. Acesso em: 11 mai. 2016.

Corte Europeia de Direitos Humanos. Ruano Morcuende v. España, de 03/07/2012. Disponível em: <http://zip.net/bstqhS>.Acesso em: 11 mai. 2016.

Corte Europeia de Direitos Humanos. Stran Greek Refineries and Stratis Andreadis v. Greece, de 9/12/1994b. Disponível em: <http://zip.net/bjtpN2>. Acesso em: 11 mai. 2016.

Corte Europeia de Direitos Humanos. Tașkin and Others v. Turkey, de 10/11/2004a. Disponível em: <http://zip.net/bmtpP2>. Acesso em: 11 mai. 2016.

Corte Europeia de Direitos Humanos. Tătar v. Romênia, de 06/07/2009c. Disponível em: $\overline{<h t t p: / / z i p . n e t / b m t p Y 9>. ~ A c e s s o ~ e m: ~} 11$ abr. 2016.

Corte Europeia de Direitos Humanos. Vilnes and Others v. Norway, de 05/12/2013. Disponível em: <http://zip.net/bttqS4>. Acesso em: 22 jul. 2016.

Corte Europeia de Direitos Humanos. Winterstein and Others v. France. De 17/01/2014a. Disponível em: <http://zip.net/bntqb9>. Acesso em: 11 mai. 2016.

Corte Europeia de Direitos Humanos. Zander v. Sweden, de 25/11/1993. Disponível em: <http://zip.net/bytqh4>. Acesso em: 11 mai. 2016.

Corte Europeia de Direitos Humanos. Zielinski and Pradal and Gonzalez and others v. France, de 28/10/1999. Disponível em: <http://zip.net/bytqh3>. Acesso em: 11 mai. 2016.

Parlamento e Conselho da União Europeia. Directiva 2003/4/CE de 28 de Janeiro de 2003 relativa ao acesso do público às informações sobre ambiente (2003f). Disponível em: $<$ http://zip.net/bvtqxM $>$. Acesso em: 22 jul. 2016.

Parlamento e Conselho da União Europeia. Diretiva 2003/35/CE, de 26 de Maio de 2003, que estabelece a participação do público na elaboração de certos planos e programas relativos ao ambiente (2003g). Disponível em: <http://zip.net/bttqR4>. Acesso em: 22 jul. 2016.

Parlamento e Conselho da União Europeia. Recommendation 1614 (2003): Environment and Human Rights (2003e). Disponível em: <http://zip.net/bbtp39>. Acesso em: 22 jul. 2016.

Protocolo n. 1 à Convenção Europeia de Direitos Humanos, 1952. Disponível em: $\overline{<h t t p: / / z i p . n e t / b g t p J y>. ~ A c e s s o ~ e m: ~} 11$ fev. 2016.

GOMES, Carla Amado. Textos Dispersos de Direito do Ambiente. V. III. Lisboa: Associação Acadêmica da Faculdade de Direito, 2010.

ITÁLIA. Conselho de Estado. Sent. 1220/2010, de 19/01/2010. Disponível em: <http://zip.net/bltpvR>. Acesso em: 11 jul. 2016. 
ITÁLIA. Corte Constitucional. Sent. 113/2011, de 04/04/2011. Disponível em: <http://zip.net/bltpvQ>. Acesso em: 11 jul. 2016.

JACOBS, Francis. The Role of the European Court of Justice in the Protection of the Environment. Journal of Environmental Law, v. 18, n. 2, p. 185-205, 2006.

MCHARG, Aileen. Reconciling Human Rights and the Public Interest: Conceptual Problems and Doctrinal Uncertainty in the Jurisprudence of the European Court of Human Rights. The Modern Law Review, v. 62, n. 5, p. 671-696, 1999.

NOGUERA, Antonio V. Derechos Humanos y Medio Ambiente en el Tribunal Europeo de Derechos Humanos: Breves Notas para el Futuro Contexto Internacional. Revista Penal, v. 30, p. 146-157, 2012.

SHELTON, Dinah. Whiplash and Backlash - Reflections on a Human Rights Approach to Environmental Protection. Santa Clara Journal of International Law, v. 13, n. 2, p. 11-29, 2015.

SIMS, John C. Compliance without Remands: The Experience under the European Convention on Human Rights. Arizona State Law Journal, v. 36, n. 2, p. 639-660, 2004.

SPIELMANN, Dean. Allowing the Right Margin. The European Court of Human Rights and the National Margin of Appreciation Doctrine: Waiver or Subsidiarity of European Review?. Cambridge Yearbook of European Legal Studies, v. 14, p. 381-418, 2012.

UNIÃO EUROPEIA. Tratado da União Europeia (TUE), com a redação final dada pela Acta de Retificação assinada em Roma, em 27 de Novembro de 2009a. Disponível em: <http:/ zip.net/bytqd2>. Acesso em: 15 dez. 2015.

Tratado de Funcionamento da União Europeia (TFUE), com a redação final dada pela Acta de Retificação assinada em Roma, em 27 de Novembro de 2009b. Disponível em: <http:/ /zip.net/bytqd2>. Acesso em 15 dez. 2015.

VEDASCHI, Arianna. L'ouverture del Tribunale Federale svizzero alla giurisprudenza delle Corti europee. In FRANCO, Giuseppe (coord.). Corte Nazionali e Corte Europee. Napoli: Ed. Scientifiche Italiane, p. 283-326, 2006.

Trabalho enviado em 08 de setembro de 2016.

Aceito em 01 defevereiro de 2017. 